\title{
Avaliação da tecnologia das relações de cuidado nos serviços em saúde: percepção dos idosos inseridos na Estratégia Saúde da Família em Bambuí, Brasil
}

\author{
Assessment of the technology of care relations \\ in the health services: perception of the elderly \\ included in the family health strategy in Bambuí, Brazil
}

Wagner Jorge dos Santos ${ }^{1}$

Karla Cristina Giacomin ${ }^{2}$

Josélia Oliveira Araújo Firmo ${ }^{2}$

${ }^{1}$ Programa de PósGraduação em Saúde Coletiva, Centro de Pesquisas René Rachou, Fiocruz. Av. Augusto de Lima 1715/610, Barro Preto. 30.190-002 Belo Horizonte MG Brasil.wagnerjorge@ cpqrr.fiocruz.br

${ }^{2}$ Núcleo de Estudos em Saúde Pública e Envelhecimento, Fiocruz.

\begin{abstract}
In the health field, technologies of care relations are in the scope of the worker-user encounter, implying intersubjectivity with the development of relationships between subjects, resulting in action. Evaluation studies synthesize knowledge produced on the consequences of using these technologies for society. This anthropological study aims to understand the perception of the elderly regarding the resolution capability and effectiveness of the acts produced in health care relationships in the context of the Family Health Strategy (ESF). The group studied consisted of 57 elderly residents in Bambui, State of Minas Gerais, Brazil. The model of signs, meanings and actions was used for collecting and analyzing data and the semi-structured interview was applied as a research technique. Elderly individuals assess resolution capability and effectiveness of the acts of care in the ESF as negative, with relation to the quality of user and professional interaction. The ESF is not effective and the desired change in the health care model has not occurred in practice. It repeats the centrality of the medical-drug-procedure model that treats the disease rather than the patient, perceiving old age as a disease and illness as being related to aging.
\end{abstract}

Key words Health assessment, Technology applied to the health services, Health services for the elderly, Elderly individuals
Resumo No campo da saúde as tecnologias das relações de cuidado se inscrevem no espaço do encontro trabalhador-usuário, implicando intersubjetivamente com a produção de relações entre sujeitos, materializando-se em ato. Estudos de avaliação sintetizam conhecimentos produzidos sobre as consequências da utilização dessas tecnologias para a sociedade. Esse estudo de cunho antropológico visa compreender a percepção dos idosos sobre a capacidade resolutiva e efetividade dos atos em saúde produzidos nas relações de cuidado contextualizadas na Estratégia Saúde da Família (ESF). O universo pesquisado foi composto por 57 idosos residentes em Bambuí (MG). O modelo dos Signos, Significados e Ações foi utilizado na coleta e análise dos dados, aplicando como técnica de pesquisa a entrevista semiestruturada. Os idosos avaliam a capacidade resolutiva e efetividade dos atos de cuidado na ESF como negativa, tendo como referência a qualidade das interações entre usuário-profissional. A ESF não é efetiva e a desejada mudança do modelo assistencial não ocorreu na prática: repete a centralidade do modelo médicomedicamento-procedimento que cuida da doença e não do doente, compreendendo a velhice como doença e os agravos como coisas da idade.

Palavras-chave Avaliação em saúde, Tecnologia aplicada aos serviços de saúde, Serviços de saúde para idosos, Idoso 


\section{Introdução}

O trabalho humano é uma atividade social que, no campo da saúde, assume um caráter interativo e comunicativo, visto que as ações de saúde ocorrem no âmbito do encontro profissional-usuário ${ }^{1}$. No entanto, sob a ótica marxista, o trabalho é considerado não somente em sua dimensão operativa - enquanto uma atividade -, mas como uma práxis que expõe a relação homem/mundo em um processo de mútua produção ${ }^{2}$, sendo que a essência dos serviços se fundamenta no sentido da realização de trabalho em processo ${ }^{3}$.

No âmbito da saúde, os serviços são trabalho em ação cujo fluxo tem como atributos: a intangibilidade, a simultaneidade, a inestocabilidade e a irreversibilidade ${ }^{3}$. Intangível, pois como processo não se associa ao produto resultante; simultâneo, porque a prestação de serviço acontece pari passu ao consumo, da demanda ao atendimento; inestocável, porquanto seu fornecimento é contínuo no tempo e no espaço, mas extingue-se ao seu final; e irreversível: pode-se interrompê-lo, mas não revertê-lo, pois parte da ação e efeito já aconteceu ao longo do processo ${ }^{3}$.

Além disso, o conjunto dos trabalhos em Saúde gera um produto caracterizado como atos de saúde, capazes de intervir no mundo denominado problema de saúde e alterá-lo ao produzir como resultado a satisfação de uma necessidade/ direito do usuário final ${ }^{4}$. Por sua vez, o tipo de modelo assistencial assumido pelos trabalhadores da saúde bem como sua forma de organização e de intervenção são determinados com base nas concepções de homem/mundo e dos processos saúde/doença. Na forma como o profissional da saúde interage, principalmente o médico ${ }^{5} \mathrm{com}$ os usuários e outros profissionais, pode predominar o lado duro (instrumental) ou leve (relacional) de seu projeto assistencial e prática clínica. $\mathrm{Na}$ abordagem assistencial de um trabalhador da saúde junto a um usuário-paciente, configura-se um processo de relações ${ }^{4} \mathrm{em}$ que há o encontro entre duas pessoas que atuam uma sobre a outra, e onde se opera um jogo de expectativas e produções, criando-se intersubjetivamente momentos de falas, escutas e interpretações. É nessa dimensão relacional do campo da saúde que se produzem ou não atos de: acolhimento das intenções que essas pessoas colocam nesse encontro; cumplicidade, com responsabilização em torno do problema a ser enfrentado; confiabilidade e esperança, que geram relações de vínculo e aceitação ${ }^{4}$.

Porém, o paradigma estruturante do modelo assistencial atual, que configura a maneira do médico atuar, vive uma crise marcada por: distanciamento dos interesses dos usuários; isolamento na sua relação com outros profissionais de saúde e desconhecimento da importância de suas práticas; predomínio de intervenções centradas em tecnologias de equipamentos e máquinas, a partir de um saber estruturado e quase reduzido aos procedimentos ${ }^{4}$. Ainda assim, o trabalho em saúde não pode ser expresso em equipamentos e saberes tecnológicos estruturados ${ }^{6}$ nem as tecnologias em saúde confundidas ou resumidas ao sentido material de um conjunto de equipamentos tecnológicos de trabalho ${ }^{7}$. Afinal, a tecnologia ligase também ao "saber fazer" e a um "ir fazendo", na medida em que suas ações mais estratégicas configuram processos de intervenção e operam como tecnologias de relações, de encontros e de subjetividades. Quando o trabalhador em saúde realiza o cuidado e a atenção ao usuário, opera um núcleo tecnológico em seu processo de trabalho composto por Trabalho Morto (instrumental) e Trabalho Vivo em ato: o primeiro refere-se a instrumentos aos quais já se aplicou um trabalho pregresso para sua elaboração e o segundo, ao campo social próprio das tecnologias das relações entre sujeitos ${ }^{9}$. Eles formam uma razão entre si estabelecendo uma Composição Técnica do Trabalho, que pode trazer a hegemonia do Trabalho Morto, quando o modelo assistencial se caracteriza como médico hegemônico, produtor de procedimentos; ou potencializar o Trabalho Vivo, quando este modelo opera linhas de cuidado centradas nas necessidades do usuário?.

Diante do intenso processo de envelhecimento populacional brasileiro, fenômeno que redimensiona todas as políticas sociais, especialmente a saúde pública, esse estudo objetiva compreender, a partir da visão dos idosos, a capacidade resolutiva quanto às suas demandas e efetividade dos atos em saúde produzidos nas relações de cuidado contextualizados na Estratégia Saúde da Família (ESF) do município de Bambuí, Minas Gerais.

\section{Quadro Teórico}

Fundamentada na corrente interpretativa da Antropologia, na qual emerge uma nova concepção da relação entre indivíduos e cultura ${ }^{10}$, a presente pesquisa utiliza a concepção geertziana ${ }^{11}$ de cultura como um universo de símbolos e significados que permite aos sujeitos de um grupo interpretar suas experiências e guiar suas ações. Este contexto confere inteligibilidade a situações e acontecimentos da vida, estruturando o campo social em um tecido semântico; um texto interpretável. 
A antropologia para saúde constrói um quadro conceitual e metodológico inovador que investiga o envelhecimento a partir da perspectiva êmica ${ }^{12}$, sendo a interpretação do cientista elaborada na visão dos entrevistados e não naquela do pesquisador ou da literatura ${ }^{13}$. Nessa perspectiva, o idoso é convocado a falar sobre a vida e sobre si, mais especificamente sobre suas condições de saúde e sua inserção e interação no campo da saúde, possibilitando ao pesquisador o mergulho no ambiente local e cultural do sujeito idoso, onde ele se organiza e confere significados particulares a sua própria experiência.

Essa pesquisa se baseou na definição de tecnologia como escopo de saberes que permitem operar sobre recursos disponíveis na realização de objetivos e finalidades almejadas e postas para a especificidade de um processo produtivo ${ }^{7,14}$. No campo da saúde, as tecnologias envolvidas nos serviços podem ser classificadas em: tecnologias duras, como os equipamentos tecnológicos do tipo máquinas, normas, estruturas organizacionais; tecnologias leve-duras, como os saberes bem estruturados que operam no trabalho em saúde; tecnologias leves, que são as tecnologias de relações do tipo produção de vínculo, autonomização, acolhimento e gestão como uma forma de governar processos de trabalho ${ }^{15-17}$. Em sua intervenção, o médico utiliza três tipos de valises com diferentes ferramentas: a primeira, à sua mão, contém tecnologias duras (equipamentos como estetoscópio, ecógrafo, etc.); a segunda, em sua cabeça, tecnologias leve-duras (conhecimentos e saberes como a clínica e a epidemiologia); e a terceira, presente no espaço relacional trabalhador-usuário, tecnologias leves, implicadas intersubjetivamente com a produção das relações entre dois sujeitos, tendo somente materialidade em ato ${ }^{15}$. As tecnologias leves fundamentam o objeto e objetivo do presente trabalho.

A Avaliação das Tecnologias em Saúde (ATS) ${ }^{18}$ pode ser definida como estudos que procuram sintetizar conhecimentos produzidos sobre as consequências para a sociedade da utilização dessas tecnologias de atenção à saúde, subsidiando decisões relativas à sua difusão e incorporação. A ATS tem-se mostrado um importante instrumento para o planejamento e a gerência das ações de cuidado, servindo de subsídio crítico baseado em evidências à elaboração de diretrizes clínicas e padrões de qualidade dos processos e contribuindo para a melhoria da qualidade e efetividade da atenção nos sistemas de saúde ${ }^{18}$.

\section{Percurso Metodológico}

Os pressupostos da abordagem qualitativa foram utilizados no presente estudo de cunho antropológico. O método de coleta de dados foi baseado no contato direto intersubjetivo entre o pesquisador e o sujeito pesquisado, sendo estabelecido o ambiente natural do sujeito como o espaço inequívoco onde ocorre a observação sem controle das variáveis e sem produzir nele nenhuma modificação ${ }^{19}$.

O modelo de Signos, Significados e Ações, desenvolvido por Corin et al. ${ }^{20}$, utilizado na coleta e análise dos dados, origina-se na corrente interpretativa da antropologia e permite a sistematização dos elementos do contexto que participam da construção de maneiras típicas de pensar e agir dos sujeitos idosos pesquisados face a atos e serviços de saúde. Esse modelo possibilita o acesso às lógicas conceituais privilegiadas da população pesquisada para compreender e explicar sua condição de usuária nos serviços de saúde, assim como identificar os diferentes elementos do contexto que intervêm na construção de comportamentos concretamente adotados frente ao problema ${ }^{10,21}$.

O estudo foi desenvolvido entre abril e agosto de 2010, na sede do município de Bambuí (MG), que dispõe de seis unidades básicas de saúde (UBS), cada uma delas com uma Equipe de Saúde Família (um médico, um enfermeiro, um técnico de enfermagem e um auxiliar de enfermagem e seis a sete agentes comunitários de saúde) funcionando na lógica territorial, dividida em áreas e micro-áreas. A cidade conta com uma equipe do Núcleo de Apoio à Saúde da Família formada por um fisioterapeuta, um nutricionista, um psicólogo e um fonoaudiólogo.

Os critérios de inclusão buscaram garantir a heterogeneidade dos participantes idosos quanto a: território das equipes da ESF, gênero, idade e condição funcional. Somente foram entrevistados idosos sem alterações cognitivas ${ }^{22}$, que impedissem a realização das entrevistas. O critério de saturação regulou o tamanho do grupo ${ }^{23}$.

A técnica de pesquisa, entrevista individual com roteiro semiestruturado, permitiu a ampliação do campo de fala dos idosos pertencentes ao universo pesquisado. As entrevistas tiveram inicialmente as seguintes perguntas geradoras: Como você acha que está sua saúde? Para você, o que é uma saúde boa? E saúde ruim? Como é o seu dia-a-dia, sua rotina? Como é um dia em sua vida? A partir das respostas obtidas, outras 
perguntas foram feitas de maneira aberta abordando o contexto biopsicossocial, os recursos, o impacto e o significado da incapacidade. Todas as entrevistas foram realizadas nos domicílios, gravadas e transcritas, permitindo na leitura atenta a identificação da unidade de significado associada aos atos e serviços de saúde e suas várias categorias analíticas, fundamentando a análise na interação entre as diferentes categorias e sua articulação com o contexto sociocultural vigente ${ }^{24}$.

Esta pesquisa é parte do projeto "Abordagem Antropológica da Dinâmica da Funcionalidade em Idosos", aprovado pelo Comitê de Ética em pesquisa com seres humanos do Centro de Pesquisa René Rachou. Todos os participantes assinaram termo de consentimento, em acordo com a Resolução n¹96/1996²5 do Conselho Nacional de Saúde.

\section{Resultados e Discussão}

O presente trabalho traz à luz a percepção dos idosos acerca da atenção à saúde, a partir de seu encontro e interação com os profissionais no cotidiano dos serviços. $\mathrm{O}$ universo pesquisado foi composto por 57 idosos (27 homens e 30 mulheres), com idades entre 61 e 96 anos, assistidos pela ESF. Quanto ao estado civil, 24 eram casados, sete solteiros, 25 viúvos e um vivia em união estável; a maioria com filhos. No grupo, prevalecem baixa escolaridade, forte predomínio da religião católica e origem rural, sendo razão de mudança para a cidade a maior proximidade com o serviço de saúde e/ou com a escola dos filhos.

$\mathrm{Na}$ análise do campo de fala dos idosos não foi observada diferença entre a concepção de homens e mulheres sobre o tema estudado, ao mesmo tempo em que o sujeito idoso faz uma avaliação da sua experiência corporal de incapacidade considerando o seu quadro de referência pessoal, sustentado nos dados da cultura que confere significado à sua experiência ${ }^{26}$. Após várias leituras das entrevistas, sob um olhar específico e cuidadoso, foi possível identificar como unidade de significado a percepção do sujeito idoso sobre a relação profissional-usuário nos atos de saúde.

Foram discriminadas quatro categorias analíticas de acordo com os signos percebidos e associados pelos sujeitos pesquisados: concepção da experiência de saúde / doença / incapacidade; avaliação dos serviços de saúde com base na produção do vínculo; prática de acolhimento no processo de interação/intervenção e autonomia do usuário. Esse recorte representa o sentido das ideias dos sujeitos pesquisados.

\section{Concepção da experiência de saúde / doença/incapacidade}

Nessa categoria, a dimensão humana no campo das relações modifica a experiência. Adoecer é uma experiência que promove a aproximação das pessoas, media encontros e reforça conhecimentos de amizades e cuidado, conforme relata uma idosa: Aqui é bom demais! Estes vizinhos é uma família [...] quando eu adoeço, não falta gente: é carro para me levar, é para ficar comigo no Hospital. São gente boa. (M24, 86 anos, viúva). Nesse sentido, tal experiência também se inscreve no contexto como dado da cultura, conferindo à prática da visita um significado que integra o olhar destinado ao sujeito doente, conforme visto a seguir: A gente visita quando morre alguém; quando tem uma doença. (M33, 74 anos, viúva); Faço visita pra alguma pessoa que eu sei que às vezes tá doente [...] a gente só vai na casa de uma pessoa que tá doente, perguntar se melhorou, as forças que a gente puder dar a ele, a gente dá. (H12, 70 anos, solteiro). A visita é, portanto, o espaço privilegiado em que se estabelecem relações de cuidado, aonde o cuidador do campo social, idoso ou não, vai à casa do sujeito que precisa de cuidado. Metáfora similar que a cultura empresta aos modos de se fazer a clínica na ESF.

Porém, adoecer pode igualmente constituir uma experiência de afastamento do outro, na medida em que o cuidar convoca o sujeito que cuida a dar de si, e isso dá trabalho, como explica uma idosa solteira: Ih, a gente fica doente, a gente dá trabalho demais! Parece que eu perdi a coragem! Ah não! Deus me livre! Mainha... eu passava a noite toda sem dormir com ela e no outro dia tinha que trabalhar. Indagada se tem amigas, a mesma senhora responde: Ah, ter tem! Assim, mas quando a gente fica doente, eles afasta tudo da gente. Não sei o quê que é... (M27, 80 anos). Quanto ao processo saúde/doença, outra idosa responde se é comum as pessoas ficarem interessadas nos problemas de outrem: Não. Às vezes. Nas horas boas, tem. Nas horas de doença, às vezes, tem. A gente ainda tem muita gente (M10, 72 anos, casada). Assim, o campo social das interações fornece à experiência da saúde/doença os sentidos do encontro entre subjetividades que se reconhecem como sujeito que cuida e sujeito que é cuidado, aquele que recebe/aquele que doa, quem é alvo do trabalho/ quem trabalha cuidando.

No grupo pesquisado, embora o termo "incapacidade funcional" não apareça nas falas dos entrevistados, essa condição, temida como provável destino dos idosos, é reconhecida no signo não dar 
conta de fazer alguma atividade. No cuidado desse corpo que envelhece e experimenta a incapacidade, a dificuldade do sujeito que precisa de cuidados não se dá no acesso aos objetos, mas sim no acesso às pessoas, conforme explicam uma idosa: [precisa de ajuda pra ir ao médico?] Sempre a minha sobrinha vai comigo (M27, 80 anos, solteira); e um idoso: tenho que esperar um passar: 'fulano, pega isso pra mim!' (H15, 79 anos, casado). Assim, no campo social das tecnologias das relações, a pessoa idosa pode encontrar (ou não) os sentidos fundamentais para sua experiência de envelhecer com incapacidade, vivenciar a dependência e convocar uma alteridade para o lugar da função faltante de seu corpo.

Ademais, a construção das práticas assistenciais de cuidado ainda perpassa a pesquisa e a detecção de doenças e de seus agravos e a pessoa idosa com suas múltiplas queixas apenas reproduz e reforça o modelo que reduz a velhice às doenças, como relata esse idoso: Há um ditado que fala assim: senectus esculopus, a velhice é doentia. Eé. (H15, 79 anos, casado). Assim, a cultura confere ao profissional o sentido de uma prática que cuida da doença e não do doente, deslocando-se do encontro entre subjetividades e transformando o sujeito idoso em uma categoria nosológica.

\section{A avaliação dos serviços de saúde com base na produção dos vínculos}

No campo de fala dos idosos, ao avaliar os serviços de saúde, chama atenção a importância que é dada ao encontro entre o sujeito idoso e o profissional de saúde. Os profissionais citados são avaliados em função da empatia (ou falta dela), da qualidade das interações e do tratamento recebido no centro de saúde, conforme constatado nos relatos selecionados. Uma idosa, referindo-se às agentes de saúde, afirma: as moça são muito boa, trata a gente bem (M24, 86 anos, viúva, grifo nosso). Outros dois atestam a possibilidade de haver relações desrespeitosas nas tecnologias do cuidado. Uma senhora afirma: $O$ doutor $X$ é bom médico. $E$ ele é bom mesmo. Eles reclama dele, que ele é muito bruto. Comigo ele não é bruto, mas também a pessoa vai com brutalidade, [...] ele não é obrigado não. Eu acho ele ótimo! Conversa comigo, conta caso da vida dele. (M14, 88 anos, viúva, grifo nosso). A fama de agir com brutalidade, código que se inscreve a partir da percepção de outros idosos da cidade, é questionada a partir da singularidade do seu encontro com o profissional, que lhe outorga certa intimidade e a quem confere o status de "bom médico". Outra mulher, ao dizer se o serviço de saúde melhorou com a ESF, evoca o significado de não ser maltratada como uma singularidade das tecnologias em saúde presente na sua experiência atual com auxiliares de enfermagem, e sustenta, a partir daí, uma avaliação positiva dos serviços: Olha, mudou, porque às vezes as meninas vêm e medem a minha pressão. Aí mede a pressão, aí depois, às vezes, a menina traz o médico aqui. É só marcar e ele vem, atende a gente direitinho, é muito educado, trata a gente bem, não maltrata a gente (M13, 66 anos, viúva, grifo nosso). Um senhor explica: Tem um médico que é conhecido, então eu tenho aquela confiança de conversar com ele. Que nem eu falei pra ele: 'eu quero consultar com o senhor. [...] o senhor achar, o senhor me esclarecer, que eu acho que é bom saber o quê que tá acontecendo. (H7, 84 anos, casado).

Na composição do campo relacional em saúde do universo pesquisado, a avaliação baseia-se diretamente na relação pessoa idosa-profissional, como este a acolhe e conduz no serviço, mas persiste forte componente de centralização e de supervalorização da figura do médico nas práticas em saúde ${ }^{27}$ ao olhar a atenção à saúde a partir desse único recorte profissional. Assim, as relações usuário idoso-profissional de saúde ainda se estabelecem na perspectiva de poder, desigualdade e distanciamento, dificultando o encontro. Portanto, para que o cuidado seja efetivo/afetivo, é necessário reconfigurar essas tecnologias das relações não como sujeito-objeto, mas sujeito-sujeito, reconhecendo nas singularidades os lugares de troca. Assim, os sentidos que determinam as relações no campo da saúde serão estabelecidos não como domínio de uma pessoa sobre a outra, mas como convivência e encontro, onde as intencionalidades se estabelecem com o sentido de interação com o outro ${ }^{28}$.

Quando questionada sobre a avaliação que fazia do serviço de saúde, outra senhora afirma: Ah melhorar não melhora, não... É sempre assim, sempre uma pessoa reclama uma coisa, sempre uma pessoa reclama outra, negócio de médico, negócio de atendimento. [...] Todo mundo aqui, muita gente mesmo reclama aqui negócio de saúde. Tem coisa aqui que, se não correr pra fora, morre (M17, 61 anos, casada). Essa avaliação negativa da capacidade resolutiva do serviço público de saúde em atender as necessidades e expectativas dos usuários foi recorrente, conforme evidenciado na fala de outro idoso: ... eu tava sentindo uma falta de ar e doía um pouquinho. Deitava e não sentia nada. Quando dava a falta de ar, aquela dorzinha. Consultei com os médicos aqui, quase, eu posso falar que com eles todos. Fiz exame, não adiantou 
nada. Já vai lá, já vai e não dá nada e o problema na mesma. [...] o médico pediu ultrassom, mas pra mim fazer tudo aqui é difícil. Fiz os exames, fiz a ultrassom aqui no Dr. X e não deu nada. Não deu nada e o problema a mesma coisa. (H7, 84 anos, casado). O usuário não reclama da falta de conhecimento tecnológico no atendimento, mas da falta de interesse e de responsabilização dos diferentes serviços acerca da sua pessoa e do seu problema em particular ${ }^{4}$. Do ponto de vista dele, o conjunto dos serviços públicos ou privados ofertados, com raras exceções, ainda não é adequado para resolver seus problemas de saúde, tanto no plano individual quanto coletivo ${ }^{4}$.

Quanto ao acesso à equipe da ESF, uma idosa relata: ... consulto diariamente porque não sara, mas a gente fica naquela fé que vai sarar, mas o médico ótimo me desanimou: 'que isso é idade, que eu tenho que aceitar. (M24, 86 anos, viúva, grifo nosso). Ao determinar pensamentos e comportamentos, mediados por normas de conduta sobre as ações cotidianas e a concepção de cuidado dos entrevistados, o saber biomédico domina a percepção que a pessoa idosa tem do processo saúde/doença/incapacidade, levando-a a interpretar suas condições de saúde e possibilidades de cuidado na direção unilateral (e usualmente negativa) do olhar que o profissional médico lhe dirige ${ }^{29}$.

Perguntada em que os serviços de saúde poderiam melhorar, uma idosa responde: Porque tem dia que ele [o médico] não tá aqui, ele não fica aqui direto. Ele vai pra policlínica. Às vezes, a pessoa precisa e tem que correr pra lá. Questionada sobre se melhoraria sua assistência se o médico ficasse no posto, acrescenta: Melhorava pra todo mundo, não é só pra mim, não (M13, 66 anos, viúva). Portanto, não se trata da má gestão dos serviços, mas da percepção de abandono e desamparo à qual os sujeitos pesquisados são submetidos pelos profissionais no serviço público, a ponto de um idoso justificar a sua decisão de não ir mais ao posto de saúde e preferir consultar, no meio privado, com o mesmo profissional que poderia atendê-lo pelo SUS: Eu já consultei com ele no posto, umas quatro [vezes] ... mas vou te contar a verdade, eu acho que é. Eu não sei se os outros acha também. As consultas que ele fez pelo SUS, pagando a receita, eu acho que ela é mais encaminhada (H7, 84 anos, casado, grifo nosso). Na visão do entrevistado, a consulta paga mostra-se mais satisfatória do que quando realizada no serviço público.

\section{Prática de acolhimento no processo de interação/intervenção}

No universo pesquisado, foi possível identificar as práticas em saúde no cotidiano dos serviços de maneira bastante reveladora. Acolhimento, escuta, cuidado competente, responsabilização, estímulo à autonomia e vínculo são etapas esperadas de uma efetiva linha de cuidado.

No acolhimento, arranjo tecnológico que se dá mediante uma primeira atenção ao usuário, busca-se escutar todos os pacientes, solucionar os problemas mais simples e/ou garantir o encaminhamento pertinente assegurando o acesso universal dos usuários ${ }^{30}$. As práticas de acolhimento buscam inverter o modelo tecnoassistencial na saúde, organizando-o de maneira usuário-centrado, respeitando princípios que garantam a acessibilidade universal, a reorganização do processo de trabalho com o deslocamento do eixo central do médico para a equipe multiprofissional e a qualificação da relação trabalhador-usuário, a partir de parâmetros humanitários de solidariedade e cidadania $^{31}$.

Contudo, na percepção do universo pesquisado, o modo de acolhimento do profissional médico revela pressa no atendimento, comprometendo a resolutividade e a efetividade das ações em saúde. Um idoso relata o longo trajeto de busca da solução de seu problema, sem, contudo, obter êxito: Uma vez eu dei uma diarreia, aí eu fui no doutor X. Ele falou:' vai fazer três exames de fezes'. Eu fiz quatro. Foi engraçado. Aí cheguei pra ele e falei: eu fiz o exame de hanemopata [referindo-se ao enema opaco]. É um exame que você toma Laxol, toma Lactopurga, depois limpa tudo por dentro e eles injeta um liquido branco pra estimular as tripas pra fazer radiografia. 'Olha você não tem inflamação nenhuma!' Como não era um médico muito com pressa: 'eu vou resolver esse problema seu'. Se fosse um outro, se fosse um outro médico do PSF, eu não vou fazer nada, eu vou embora (risos) (H47, 69 anos, casado, grifo nosso).

Quanto à capacidade de escuta, uma idosa reclama: [...] a gente não precisa falar muita coisa que eles já tão dando a receita. (M35, 93 anos, viúva). Novamente se observa uma prática clínica medicamento-centrada, e não usuário-centrada, como defendido pela medicina da comunidade ${ }^{32}$.

Nas práticas de saúde relatadas, valoriza-se o cuidado que beneficia consulta a especialistas e o uso continuado de medicamentos para tratar problemas de saúde, conforme fala essa senhora: Eu tenho Chagas, eu tenho é... essa tremura, Parkinson. Eu trato com um neurologista de [uma 
cidade próxima]. Ele falou pra mim: 'ó dona $M$., não tem cura, mas tem melhora. Se a senhora tomar os remedinhos direito e todos os remédios que eu tô receitando a senhora vai melhorando'. Na verdade, eu tô melhorando, alivia demais (M51, 70 anos, viúva). Neste quadro, o cuidado integral resta comprometido pelo despreparo do profissional em lidar com situações incuráveis e demandas reveladoras da finitude humana ${ }^{33}$.

Quanto à frequência de consulta ao serviço, um entrevistado relata: Vou ao médico diário, sô. Meu Doutor é o X [...] aí dá aquela perrengada, ele arranja aquele remédio e fala: 'Cê leva esse e vai tomando, acaba uma receita e pega outra e, na hora que piorar mais, cê volta (H23, 82 anos, casado, grifo nosso). Essa fala, provavelmente, reflita a impotência do profissional médico em lidar com condições crônicas que requeiram cuidados permanentes, pois este profissional usualmente é treinado para interceder em casos agudos ${ }^{29}$. Porém, ao fazê-lo admite-se a aceitação tácita daquilo que o saber biomédico preconiza para lidar com doenças crônicas e incuráveis, induzindo, simultaneamente, um olhar estereotipado para a especificidade das questões de saúde na velhice, conforme atesta um idoso: [...] [o médico] só falou comigo assim: 'o senhor não preocupa muito, não. Caça um jeito de ficar mais despreocupado, repouso, isso maior que você sente agora é idade. Essa idade da gente aparece uma coisinha aqui, aparece outra por lá, o senhor não tem que preocupar, não. (H7, 84 anos, casado). Esse olhar do profissional sobre a velhice, carregado de negativismo, favorece equivocadamente a naturalização das doenças na velhice e a compreensão dessa etapa da vida como um fenômeno homogêneo ${ }^{29}$. Além disso, reforça códigos da cultura naturalmente aceitos e presentes nas representações e no discurso sobre o corpo e a saúde dos idosos, a partir de estereótipos negativos em torno da outra díade indissociável velhice/doença ${ }^{34}$ que reconhecem a incapacidade como "companheira inexorável" da velhice.

Embora a atenção aos usuários seja fundamental, uma idosa revela dificuldades para resolver sua demanda na ESF: Ontem, minha sobrinha veio aqui fazer um curativo para mim, porque aquele povo do postinho é muito enrolado e não vem. Se não fosse minha sobrinha, eu mesma tinha que fazer [...] Tem uma que passava quase todo dia, agora sumiu. Meio enrolada. (M27, 80 anos, solteira, grifo nosso). Essa dificuldade de comprometimento na resolução dos problemas de saúde, sempre presente na interação usuário-profissional, expõe o sentido de impessoalidade implícito à prática médica. Um idoso responde se algum médico já se preocupou com o fato de ele não estar andando: Ah, preocupa os filhos. [Os filhos preocupam?] $A h$, eles preocupam, porque vê eu desse jeito. Mas os outros, não. De fora, não (M8, 83 anos, viúva). Outro idoso afirma: Ah... é pelo meu problema, os médicos do postinho parece que não é, parece que não é suficiente, não é especializado (H11, 69 anos, casado). Talvez, a fragmentação imposta pelo saber das especialidades médicas impeça o sujeito de ser visto na sua totalidade ${ }^{35}$, conferindo insuficiência ao saber e à prática médica.

\section{A autonomia do usuário}

Essa categoria demonstra obstáculos à autonomia dos usuários idosos. O saber biomédico, inserido nas relações médico/paciente, tutela o saber/fazer em saúde produzindo o efeito de culpabilização pela sua condição atual de saúde $e^{29}$ conforme o registro da fala de um médico, que aponta como causalidade das doenças os excessos cometidos no passado: Às vezes que eu fui consultar em Belo Horizonte o médico falou: 'ah, essas coisas assimé que quando você era novo você obrigou muito a trabalhar, sabe'? Ai a gente fica mais coisa assim, né? (H20, 69 anos, solteiro). A ideia de velhice como encargo individual é assimilada culturalmente pelo profissional médico, enquanto os agravos de saúde na velhice são traduzidos como de responsabilidade do idoso, "coisas da idade". Mas não se questiona o que determinou as condições de trabalho daquela pessoa em sua juventude.

Nota-se a crescente importância da tecnologia dura, quando perguntada sobre sua percepção da saúde uma senhora avalia: A minha saúde? Eu quando faço um exame me fala que eu não sinto nada... (M44, 69 anos, separada). O resultado dos exames chega a sobrepujar até mesmo sua subjetividade e experiência corporal, pois é o exame quem fala. Assim, o processo de construção dos atos de saúde é fundamentalmente procedimentocentrado e não usuário-centrado, na medida em que a sua finalidade última, razão pela qual ela se realiza, se esgota no si mesmo da produção técnica final do procedimento ${ }^{4}$. A insatisfação do universo pesquisado com os serviços revela o imperativo de mudança na direção de se construir o trabalho médico em um modelo assistencial centrado no usuário e tecnologia leve dependente ${ }^{4}$.

Ademais, a autonomia do idoso em contribuir com o seu próprio cuidado e aderir ao tratamento é afrontada pelo poder de tutela do profissional, no registro da fala do médico: [o médico] disse: eu vou internar você lá no sanatório. [...] Porque você não tem quem te olhe e lá você vai ter tudo e eu sou 
médico de lá e eu te dou uma olhada diária (H3, 75 anos, casado).

Finalmente, o trabalho em saúde se estabelece na produção de relações e vínculos entre as pessoas como condição fundamental para o cuidado ${ }^{8}$, no campo social das tecnologias das relações. Nesse encontro de intersubjetividades pode-se criar um vínculo e designar uma relação de ajuda-confiança entre usuário e profissional, atores sociais envolvidos no processo do cuidar, o que pode ser notado nessa fala de um idoso sobre o que o ajudou a ter saúde: Pois é, é isso que eu falo com a senhora, é os médicos ajudando a gente. (H20, 70 anos, solteiro).

Os profissionais da saúde precisam ser capacitados para a busca constante no aperfeiçoamento das relações sociais que se desenvolvem no dia a dia dos serviços, percebendo de maneira crítica os sentidos e impasses dos problemas advindos da convivência humana ${ }^{36}$. Nessa perspectiva, o instrumento principal da relação terapêutica é o próprio profissional da saúde.

Portanto, urge prosseguir na humanização das relações e potencializar a resolutividade e a efetividade dos serviços de saúde enquanto espaços de construção de vida e cidadania. Afinal, envelhecer é uma conquista recente da humanidade que pode ser vivida com mais qualidade e autonomia, quando a velhice não for considerada uma doença, quando a doença e a incapacidade na idade avançada não significarem culpa do sujeito e quando a equipe de saúde parar de entender toda condição crônica como coisa da idade.

\section{Considerações Finais}

Na fala dos idosos entrevistados, a desejada mudança do modelo tecnoassistencial com a ESF ainda não se fez na prática: repete-se a centralidade do modelo médico-medicamento-procedimento. A ESF não é efetiva na resolução das demandas específicas do idoso, pois cuida da doença e não do doente, compreendendo a velhice como doença e os agravos como coisas da idade. Apesar de todas as mudanças no paradigma da atenção à saúde, propostas pela ESF, os significados atribuídos à doença e o agir da população de idosos estudada revelam, que nas unidades com os quais tiveram contato no período observado, os serviços de saúde ainda são desenvolvidos por profissionais que focam sua intervenção na doença e na agudez dos casos e privilegiam as tecnologias duras e procedimentais, que estão diretamente atreladas a essa visão da doença como processo.

Para alterar essa realidade urge reconhecer nos serviços de saúde um campo interativo e processual, em contínuo crescimento e aprendizagem, e promover a valorização e a educação do profissional de saúde acerca do processo de envelhecimento. Nas tecnologias das relações é necessário fundamentar o respeito à velhice como etapa natural e final do curso da vida humana, que não se faz em um dia e costuma ser reveladora do cuidado que as pessoas e os serviços de saúde tiveram ao longo da vida do sujeito. Afinal, a maioria dos profissionais de saúde, inclusive o médico, chega ao campo de prática profissional sem saber lidar com a velhice e despreparada frente às condições crônicas que requerem cuidados permanentes, construídos no campo das tecnologias das relações. Além disso, o profissional de saúde ainda hoje é treinado para interceder em casos agudos, o que pode privilegiar as tecnologias duras e procedimentais em detrimento da integralidade.

\section{Colaboradores}

WJ Santos, KC Giacomin e JOA Firmo participaram igualmente de todas as etapas de elaboração do artigo.

\section{Agradecimentos}

À FAPEMIG, CNPq e CAPES pelo financiamento e à Josiane Katherine Pereira pela participação na coleta de dados. 


\section{Referências}

1. Carvalho BG, Peduzzi M, Mandú ENT, Ayres JRCM. Trabalho e intersubjetividade: reflexão teórica sobre sua dialética no campo da saúde e enfermagem. Rev. Latino-Am. Enfermagem 2012; 20(1):19-26.

2. Merhy EE, Feuerwerker LCM. Novo olhar sobre as tecnologias de saúde: uma necessidade contemporânea. In: Mandarino ACS, Gomberg E, organizadores. Leituras de novas tecnologias e saúde. Bahia: Editora UFS; 2009. p. 29-56.

3. Meirelles DS. O conceito de serviço. Rev Econ Polit 2006; 26(1):119-136.

4. Merhy EE. A perda da dimensão cuidadora na produção da saúde - uma discussão do modelo de assistência e da intervenção no seu modo de trabalhar a assistência. In: Campos CR, organizador. Sistema Único de Saúde em Belo Horizonte: reescrevendo o público. São Paulo: Xamã; 1998. p. 103-120.

5. Da Ros MA, Maeyama MA, Leopardi MT. Tecnologia na área da saúde. De que tecnologia estamos falando? Sau. \& Transf. Soc. 2012; 3(3):29-35.

6. Koerich MS, Backes DS, Scortegagna HM, Wall ML, Veronese AM, Zeferino MT, Radünz V, Santos EKA. Tecnologias de cuidado em saúde e enfermagem e suas perspectivas filosóficas. Texto Contexto Enferm 2006; 15(Esp.):178-185.

7. Pessanha RV, Cunha FTS. A aprendizagem-trabalho e as tecnologias de saúde na estratégia saúde da família. Texto Contexto Enferm 2009; 18(2):233-240.

8. Silva DC, Alvin NAT, Figueiredo PA. Tecnologias leves em saúde e sua relação com o cuidado de enfermagem hospitalar. Esc Anna Nery Rev Enferm 2008; 12(2):291-298.

9. Merhy EE, Franco TB. Por uma composição técnica do trabalho em saúde centrada no campo relacional e nas tecnologias leves. Apontando mudanças para modelos tecno-assistênciais. Saúde em debate 2003; 27(65):316-323.

10. Uchôa E, Vidal JM. Antropologia Médica: Elementos Conceituais e Metodológicos para uma Abordagem da Saúde e da Doença. Cad Saude Publica 1994; 10(4):497504.

11. Geertz C. The Interpretation of Cultures. New York: Basic Books Inc. Publishers; 1973.

12. Uchôa E. Contribuições da Antropologia para uma Abordagem das Questões Relativas à Saúde do Idoso. Cad Saude Publica 2003; 19(3):849-853.

13. Turato ER. Métodos Qualitativos e Quantitativos na Área da Saúde: Definições e seus Objetos de Pesquisa. Rev Saude Publica 2005; 39(3):507-514.
14. Merhy EE. O SUS e um de seus dilemas: mudar a gestão e a lógica do seu processo de trabalho em saúde (um ensaio sobre a micropolítica do trabalho vivo). In: Fleury S, organizador. Saúde e democracia: a luta do CEBES. São Paulo: Lemos Editorial; 1997. p. 125-141.

15. Merhy EE. Um ensaio sobre o médico e suas valises tecnológicas, contribuições para compreender as reestruturações produtivas do setor Saúde. Interface (Botucatu) 2000; 4(6):109-116.

16. Merhy EE. Em busca do tempo perdido: a micropolítica do trabalho vivo em saúde. In: Merhy EE, Onocko R, organizadores. Agir em Saúde: um desafio para o público. São Paulo: Hucitec; 1997. p. 71-112.

17. Merhy EE. Saúde: a cartografia do trabalho vivo. São Paulo: Hucitec; 2002.

18. Silva LK. Avaliação tecnológica em saúde: questões metodológicas e operacionais. Cad Saude Publica 2004; 20(Supl. 2):S199-S207.

19. Turato ER. Métodos Qualitativos e Quantitativos na Área da Saúde: Definições e seus Objetos de Pesquisa. Rev Saude Publica 2005; 39(3):507-514.

20. Corin E, Uchôa E, Bibeau G, Kouma-Re B. Articulation et variations des systèmes de signes, de sens et d'actions. Psychopathol Afr 1992; 24:183-204.

21. Firmo JOA, Lima-Costa MFF, Uchôa E. Projeto Bambuí: maneiras de pensar e agir de idosos hipertensos. Cad Saude Publica 2004; 20(4):1029-1040.

22. Lima-Costa MF, Firmo JOA, Uchoa E. Cohort Profile: The Bambui (Brazil) Cohort Study of Ageing. Int $J$ Epidemiol 2011; 40(4):862-867.

23. Fontanella BJB, Ricas J, Turato ER. Amostragem por saturação em pesquisas qualitativas em saúde: contribuições teóricas. Cad Saude Publica 2008; 24(1):17-27.

24. Giacomin KC, Uchoa E, Lima-Costa MFF. Projeto Bambuí: a experiência do cuidado domiciliário por esposas de idosos dependentes. Cad Saude Publica 2005; 21(5):1509-1518.

25. Brasil. Ministério da Saúde (MS). Conselho Nacional de Saúde. Resolução no 196 de 10 de outubro de 1996. Diretrizes e Normas Regulamentadoras de Pesquisas Envolvendo Seres Humanos. Diário Oficial da União 1996; 16 out.

26. Santos WJ, Giacomin KC, Pereira JK, Firmo JOA. Enfrentamento da incapacidade funcional por idosos por meio de crenças religiosas. Cien Saude Colet 2013; 18(8):2319-2328.

27. Rossi FR, Lima MADS. Fundamentos para os processos gerenciais na prática do cuidado. Rev Esc Enferm USP 2005; 39(4):460-468. 
28. Prochet TC, Silva MJP, Ferreira DM, Evangelista VC. Afetividade no processo de cuidar do idoso na compreensão da enfermeira. Rev Esc Enferm USP 2012; 46(1):96-102.

29. Moraes GVO. Influência do Saber Biomédico na Percepção da Relação Saúde/Doença/Incapacidade em Idosos da Comunidade [dissertação]. Belo Horizonte: Centro de Pesquisas René Rachou; 2012.

30. Carvalho SR, Campos GWS. Modelos de atenção à saúde: a organização de Equipes de Referência na rede básica da Secretaria Municipal de Saúde de Betim, Minas Gerais. Cad Saude Publica 2000; 16(2):507-515.

31. Franco TB, Bueno WS, Merhy EE. O acolhimento e os processos de trabalho em saúde: o caso de Betim, Minas Gerais, Brasil. Cad Saude Publica. 1999; 15(2):345-353.

32. Starfield B. Atenção primária: equilíbrio entre necessidades de saúde, serviços e tecnologia. Brasília: Unesco, Ministério da Saúde; 2002.

33. Giacomin KC, Santos WJ, Firmo JOA. O luto antecipado diante da consciência da finitude: a vida entre os medos de não dar conta, de dar trabalho e de morrer. Cien Saude Colet 2013; 18(9):2487-2496.

34. Uchoa E, Firmo JOA, Lima-Costa MF, Corin E. An anthropologic study on strategies for addressing health problems among the elderly in Bambuí, Minas Gerais State, Brazil. Cad Saude Publica 2011; 27(Supl. 3):s370-s377.

35. Marques GQ, Lima MADS. As tecnologias leves como orientadoras dos processos de trabalho em serviços de saúde. Rev Gaúcha Enferm 2004; 25(1):17-25.

36. Melo MC, Souza AL, Leandro EL, Mauricio HA, Silva ID, Oliveira JMO. A educação em saúde como agente promotor de qualidade de vida para o idoso. Cien Saude Colet 2009; 14(Supl. 1):1579-1586.

Artigo apresentado em 14/08/2013

Aprovado em 01/09/2013

Versão final apresentada em 03/09/2013 